Please note that this is the accepted version of this manuscript, and the published article may differ.

Reference: Matsick, J. L., Kruk, M., Palmer, L., Layland, E. K., \& Salomaa, A. C. (in press). Extending the social category label effect to stigmatized groups: Lesbian and gay people's reactions to "homosexual" as a label. Journal of Social and Political Psychology.

\title{
Extending the Social Category Label Effect to Stigmatized Groups: Lesbian and Gay People's Reactions to “Homosexual” as a Label
}

Jes L. Matsick ${ }^{* 1,2}$, Mary Kruk ${ }^{1,2}$, Lindsay Palmer ${ }^{1,2}$, Eric K. Layland ${ }^{3}$, and Anna C. Salomaa ${ }^{1}$

${ }^{1}$ Department of Psychology, The Pennsylvania State University, University Park, PA, USA.

2 Department of Women's, Gender, \& Sexuality Studies, The Pennsylvania State University, University Park, PA, USA.

${ }^{3}$ Center for Interdisciplinary Research on AIDS, School of Public Health, Yale University, New Haven, CT, USA.

\section{Author Note}

Jes Matsick ID: https://orcid.org/0000-0003-4368-3211; Mary Kruk ID: https://orcid.org/ 0000-0003-3537-0362; Lindsay Palmer ID: https://orcid.org/0000-0002-5415-9186; Eric Layland

\section{ID: https://orcid.org/0000-0003-0641-408X}

The author(s) declared no potential conflicts of interest with respect to the research, authorship, and/or publication of this article. Eric Layland received support from the National Institute on Mental Health (T32 MH020031) and National Institute on Drug Abuse (T32 DA017629). The author(s) declare no other financial support for the research, authorship, and/or publication of this article.

${ }^{*}$ Correspondence should be addressed to Jes Matsick at the Department of Psychology, The Pennsylvania State University, 416 Moore Building, University Park, PA 16803. Email: jmatsick@psu.edu 


\begin{abstract}
The social category label effect describes how labels influence people's perceptions of social groups. Though the label "homosexual" versus "lesbian/gay" decreases some heterosexual people's support for sexual minorities, it is unknown how lesbian and gay (LG) people respond to "homosexual" as a label used to describe them. Across three experiments in a largely U.S. context $\left(N_{\text {total }}=831\right)$, we examined how use of "homosexual" influenced people's responses on psychological instruments, preferences for demographic questions, and evaluations of individuals who use "homosexual." The use of different labels in psychological measures did not influence LG people's responses (Study 1). However, LG people reacted less positively to "homosexual" compared to "lesbian/gay" in demographic questions and in interpersonal exchanges (Studies 2-3), whereas heterosexual people's reactions were largely unaffected. LG people's more negative reactions to "homosexual" than "lesbian/gay" were partially explained by them perceiving the "homosexual" label user as less culturally competent (i.e., less inclusive, less engaged in LGBTQ activism). In this article, we make progress in new empirical territory (sexual orientation-based cues research), propose the notion of linguistic heterosexism, and discuss the sociopolitical implications of people's language choices.

Keywords: stigma, social category labels, LGBTQ, identity safety cues, linguistic heterosexism
\end{abstract}


"The word homosexual has several problems of designation. First, it may perpetuate negative stereotypes because of its historical associations with pathology and criminal behavior. Second,

it is ambiguous in reference because it is often assumed to refer exclusively to men and thus renders lesbians invisible."

-Committee on Lesbian and Gay Concerns, American Psychological Association (1991)

The American Psychological Association (APA, 2019) and guiding media organizations

(e.g., The New York Times, Associated Press, The Washington Post) advise against using

"homosexual(ity)" as a label to describe people with same-gender attractions and behaviors.

The Gay and Lesbian Alliance Against Defamation (GLAAD) includes "homosexual" on its list of offensive terms to avoid (GLAAD, n.d.); Dictionary.com provides a usage alert for "homosexual" and designates the term as derogatory, offensive, and archaic (Treisman, 2020); and expert of lesbian and gay history, George Chauncey, notes "(the term) 'homosexual' has the ring of 'colored' now" (as quoted in The New York Times; Peters, 2014).

The primary reason for backlash against "homosexual(ity)" is that it symbolizes the demoralizing history of criminalization and medicalization of lesbian, gay, bisexual, transgender, and queer people (LGBTQ; Herek, 2010; Herek et al., 2007). Originating in the mid-to-late $19^{\text {th }}$ century, the term "homosexuality" was used in opposition to "normal" sexuality and to represent degenerative illness and deviancy (see Katz, 1976, 1995). In particular, homosexuality was thought to reflect sexual and gender deviancy, often measured and identified through women and men's departures from conventional notions of femininity and masculinity, respectively (López-Sáez \& García-Dauder, 2020). As of 2020, anti-gay laws continue to leverage homosexual(ity) language to deem non-heterosexual activity as criminal in 78 jurisdictions worldwide (Human Dignity Trust, 2016), and until 1973, "homosexuality" was a clinical label used to diagnose and institutionalize people in the United States (U.S.). Treatment to alleviate homosexuality harnessed the most inhumane therapies known in modern history (e.g., lobotomies, castrations, electroshock therapies; see Herek, 2010; Herek et al., 2007). Despite psychology's hand in developing the model of illness surrounding homosexuality, analysis of the 
effects of continued usage of the term "homosexuality" is relatively underexamined in the psychological literature (cf. Rios, 2013).

In three experiments, we extended research on the social category label (SCL) effect to assess how lesbian and gay (LG) individuals respond to the homosexual label. Rather than assessing how labels influence prejudice toward stigmatized groups (e.g., Rios, 2013; Rucker et al., 2019), we focused on how labels impact a stigmatized group's well-being. Among LG people, we predicted the homosexual label would trigger negative feelings (Study 1), disliking for the label and unfavorable expectations for institutions that use it (Study 2), and negative evaluations of individuals who describe sexual minorities as "homosexual" (Study 3). We expected that LG people's perceptions of the label user's cultural competency (e.g., their inclusivity and commitment to social justice) would explain the SCL effect.

\section{Why Do Group Category Labels Matter?}

People have a proclivity to engage in social categorization-a process that classifies individuals into discrete categories (e.g., Allport, 1954; Brewer, 1988, 2007; Tajfel et al., 1971). As a strategy to organize and simplify information, social categorization reinforces group differentiation and concomitant intergroup processes, such as stereotyping, prejudice, and group-based hierarchies (Brewer, 2007). Sorting people into labeled groups is one way to denote group differentiation (Allport, 1954) and reproduce biases (i.e., linguistic intergroup bias; Maass, 1999). Specifically, derogatory labels can exacerbate stigma (Carnaghi \& Maass, 2007), especially when others apply derogatory labels to describe outgroups (Galinsky et al., 2013; Greenberg \& Pyszczynski, 1985). Indeed, labels could influence how people feel about that group - a process described as the social category label (SCL) effect (Crawford et al., 2016).

The SCL effect has been tested across various groups and outcomes. For example, labels influence racist and xenophobic responses: White people respond more negatively to "Black" people than "African American" (Hall et al., 2015), and Americans report more positive affect toward immigrants when immigrants are described with neutral labels (e.g., "noncitizens") 
than negative labels (e.g., "illegal aliens;" Rucker et al., 2019). Likewise, White people prompted to identify as "White" are less supportive of multiculturalism and more prejudiced than White people prompted to identify as "European American" (Morrison \& Chung, 2011). Importantly, the SCL effect is likely to change over time given that people's relationship to language continuously evolves; for example, some language will be reclaimed (e.g., "queer") or reappropriated (Galinsky et al., 2013), whereas other language that was once accepted will become outdated and discouraged.

Some research has examined how labels influence pro-LGBTQ policy support and sexual prejudice. There is less support for "homosexuals" in the military than "gay men and lesbians" (Hetchkopf, 2010), and highly authoritarian Born-Again Christians are more opposed to "homosexual" rights than highly authoritarian non-Born-Again Christians, whereas they do not differ from one another when evaluating "lesbian and gay" rights (Smith et al., 2018). Such studies suggest that homosexual labeling exacerbates opposition to pro-LGBTQ policy, especially among those who are ideologically resistant to sexual equality. In terms of how labels contribute to prejudice, heterosexual individuals express less positive feelings and associations with derogatory labels (e.g., fag) than neutral category labels (e.g., gay; Carnaghi \& Maass, 2007). "Lesbian and gay" labeling yields less sexual prejudice than exposure to the term "homosexuals" among people high in right-wing authoritarianism (Rios, 2013); however, other evidence suggests the SCL effect's bearing on sexual prejudice is weak and inconsistent (Crawford et al., 2016). However, the evidence that labels often matter when it comes to sexual orientation extends beyond the word "homosexual." When exposed to the word "straight" to describe a heterosexual person, highly religious heterosexual people more negatively evaluate a gay man-indicating that "straight" as a label can boost outgroup derogation (Sacchi et al., 2021). Finally, using stigmatizing labels can be intentional and coincide with negative emotions toward outgroups (Hall et al., 2015). For example, anti-gay campaigns promote fear of "homosexual recruitment," and homosexual labeling is often used by U.S. Republican politicians 
with anti-gay policy positions (Peters, 2014; Subtirelu, 2015). Taken together, the evidence indicates that labels related to sexual orientation matter for policy and prejudice.

Most research on the SCL effect has examined prejudice among dominant groups; Less is known about whether the effect extends to those within the labeled group. We propose that stigmatized individuals are not only attentive to the labels that others apply to them but use labels as intel to draw conclusions about others and environments.

\section{Language as Safety and Threat Cues}

Threat cues (aspects of a setting that communicate stigma) and safety cues (aspects that communicate the threat of discrimination is limited) are commonplace and hamper or strengthen stigmatized groups' psychological well-being, respectively (see Kruk \& Matsick, in press). Linguistic sexism, or gender bias in language, exemplifies how words are information sources for stigmatized groups (Gabriel \& Gygax, 2016; Menegatti \& Rubini, 2017). First establishing the effect of gender-exclusive language, Bem and Bem (1973) found that women expressed lower interest in jobs when advertisements included sex-biased wording favoring men. The effects of androcentric language are widespread (Bailey et al., 2019). For example, gender-exclusive language (i.e., he) in a job interview contributed to women's lower belonging and motivation than when gender-inclusive or neutral language was used (Stout \& Dasgupta, 2011). In contrast, the use of gender-neutral pronouns (the Swedish use of hen), lessens cognitive biases in favor of men (Tavits \& Pérez, 2019). Overall, some language cues gender bias, whereas more neutral language reduces it.

Though a substantial body of research examines identity-based threat and safety cues of gender and race (Kruk \& Matsick, in press), sexual orientation-based cues are largely ignored. Sexual minorities likely respond to cues in similar ways as heterosexual women and people of color do to gender- and race-based cues because stigmatized groups are attentive to the potential for bias (Pachankis, 2007; Vorauer, 2006). As put forward by minority stress theory (Brooks, 1981; Meyer, 2003), sexual minorities are vigilant to stigma in their environments. 
Though vigilance can be adaptive—to protect against threat-vigilance psychologically taxes stigmatized groups (Oyserman et al., 2007; Pachankis, 2007). Thus, to ensure the well-being of stigmatized groups, people should avoid using cues that could threaten them and, instead, should incorporate identity cues that instill safety (e.g., psychological belonging, trust, less anticipated stigma; Kruk \& Matsick, in press). Evidence of vigilance suggests that sexual and gender minorities are on the lookout for cues, and that cues inform their impressions of a situation. For example, Cipollina and Sanchez (2021) found that the placement of safety cues on a medical doctor's website influenced sexual minorities' perceptions of the doctor's cultural competency—suggesting that cues are not only detected but used to form evaluations about other people. In the current research, we examined if the word "homosexual" serves as a threat cue that is detected by sexual minorities and whether the cue has downstream effects on impressions and perceptions.

\section{Language as Conveying Cultural Competency}

Label use may not only impact the group targeted by the label, but perceptions of the label user. There are numerous ways in which language conveys information about the language user, but we propose one important characteristic that can be jeopardized by language use is cultural competence. Cultural competence refers to a person's ability and capacity to effectively interact with others in culturally diverse environments and to enact values that respect and promote equity and inclusion (Danso, 2018; Goodman, 2020). Most pertinent to this research, perceived cultural competence refers to judgments about people's aforementioned capacity for interacting in a culturally diverse world and valuing diversity, equity, and inclusion in their personal and professional lives. This can be accomplished via gaining expert knowledge of diverse others to promote their inclusion. Importantly, cultural competence involves multiple components (e.g., knowledge, awareness, skills; Helms \& Richardson, 1997; Sue, 2001), and various pathways exist for establishing one's cultural competence. 
Members of dominant groups who avoid using threatening cues likely exhibit some degree of cultural competence; whereas those who uphold stigmatizing language likely lack cultural competence. Enacted through verbal or non-verbal behavior, cultural competence draws upon language choices to demonstrate inclusion, acceptance, and knowledge about stigmatized groups (Botelho \& Lima, 2020; Danso, 2018; Ricca et al., 2018; Rossi \& Lopez, 2017). Signals of cultural competence are concerted actions to be inclusive and committed to diversity (Botelho \& Lima, 2020), and reflects the capacity to adopt behaviors that are respectful of cultural preferences. For example, using preferred identity labels to refer to stigmatized outgroups demonstrates sufficient training to be knowledgeable and inclusive (Rossi \& Lopez, 2017) and reflects an interest in facilitating respectful relationships (Danso, 2018; Sloboda et al., 2018). People can thus communicate their willingness to be affiliative and inclusive of others by using language to signal cultural competence.

When dominant groups use labels that are not preferred by stigmatized groups, they may perpetuate the exclusion of these groups. In workplace dynamics, for example, dominant groups can use slurs or invalidating words which communicates threat to other employees (Baker \& Lucas, 2017; Van Gilder, 2019) and can enhance other people's prejudices (Greenberg \& Pyszczynski, 1985). Someone's language could even be interpreted as lack of support and action on behalf of stigmatized groups. For example, given "homosexual" has an extensive history of pathologizing LGBTQ individuals (Rossi \& Lopez, 2017), a doctor who uses the word "homosexual" on a medical form or in patient interactions may be read as culturally incompetent, ignorant to sociopolitical conversation about LGBTQ issues, and complicit with sexual stigma. A person who uses stigmatizing labels to refer to outgroups might be showcasing their cultural incompetence by lacking understanding of sociocultural and historical contexts (i.e., knowing the preferred language of others) or intentionally using language to inflict harm.

Though seemingly essential to social and health services (e.g., psychological practice, medicine), debate surrounds the benefits of cultural competence as a construct. Many have 
noted problems with securing an agreed upon definition of cultural competence (e.g., Danso, 2018; Ridley et al., 2001; Sue, 2001). Some scholars and practitioners call to shift away from cultural competence altogether, suggesting it reproduces cultural stereotypes about groups, tokenizes outgroups, and falls short of cultural humility (for discussion, see Danso, 2018; Lekas et al., 2020). However, the establishment of the Cultural Competence for Equity and Inclusion Model builds upon basic groundwork of cultural competency while proposing a more progressive standard for cultural competence-one that sharpens skills of allyship and inclusivity, promotes institutional change, and commits to social justice (Goodman, 2020). This perspective is echoed by Sue's (2001) model that includes social justice in its conceptualization of cultural competence and by the National Association of Social Workers (2015), who state in their guidelines (p. 10): "Cultural competence also requires advocacy and activism. It is critically important to provide quality services to those who find themselves marginalized; and it is also essential to disrupt the societal processes that marginalize populations. Cultural competence includes action to challenge institutional and structural oppression and the accompanying feelings of privilege and internalized oppression." In light of recent focus on cultural competence as action, we propose that stigmatized groups consider the language that people use to determine how culturally competent they are (i.e., inclusive of and engaged in LGBTQ issues), and that cultural competence is not only characteristic of clinicians and providers but of all who participate in an increasingly diverse society.

\section{The Current Research}

In three experiments, we examined how LG people responded to the homosexual label in everyday contexts. We pursued a basic methodological question (Study 1): Does exposure to the homosexual label influence sexual minorities' responses to widely used psychological instruments? Next, we tested how LG and heterosexual people perceived the homosexual label when used in a demographic questionnaire, and we investigated the downstream implications for institutions (e.g., healthcare; Study 2). We then assessed LG and heterosexual people's 
perceptions of an individual using the homosexual label (Study 3). In Studies 2 and 3, we examined one mechanism underlying the effect of the homosexual label on participants' reactions. We theorized that perceived cultural competency would play an explanatory role in people's responses. When unfavorable or stigmatizing labels are used to refer to a group, the target group may perceive the label user as lacking cultural competence. In turn, the target group may feel negative about the label—and the people or institutions using it—because they perceive them as lacking cultural competence.

We report all experimental conditions, dependent variables, and analyses performed. The studies were not pre-registered. Supplementary material includes additional descriptive information (e.g., means), measures, open-ended questions, and materials. Data and supplementary material are available at https://osf.io/8h5fw, and all analyses were performed in SPSS (v26). In each study, we overrecruited participants given rates of exclusions in online data collection, but no additional participants were recruited after starting data analysis. We present demographic information for each sample in Table 1. 


\section{Table 1}

Sociodemographic Characteristics (Studies 1-3)

\begin{tabular}{|c|c|c|c|}
\hline Characteristic & $\begin{array}{l}\text { Study } 1 \\
(N=206)\end{array}$ & $\begin{array}{l}\text { Study } 2 \\
(N=332)\end{array}$ & $\begin{array}{l}\text { Study } 3 \\
(N=293)\end{array}$ \\
\hline Age & $M=41.77(S D=16.54)$ & $M=43.88(S D=15.18)$ & $M=43.50(S D=16.13)$ \\
\hline \multicolumn{4}{|l|}{ Sexual Orientation } \\
\hline Gay, Lesbian, Homosexual & $88 \%$ & $36 \%$ & $50 \%$ \\
\hline Bisexual & $4 \%$ & $0 \%$ & $0 \%$ \\
\hline Queer & $5 \%$ & $0 \%$ & $0 \%$ \\
\hline Heterosexual & $0 \%$ & $64 \%$ & $50 \%$ \\
\hline Unspecified & $2 \%$ & $0 \%$ & $0 \%$ \\
\hline \multicolumn{4}{|l|}{ Gender } \\
\hline Woman & $34 \%$ & $45 \%$ & $50 \%$ \\
\hline Man & $64 \%$ & $53 \%$ & $48 \%$ \\
\hline Transgender or Non-Binary & $3 \%$ & $2 \%$ & $2 \%$ \\
\hline \multicolumn{4}{|l|}{ Ethnicity/Race } \\
\hline African American/Black & $9 \%$ & $7 \%$ & $9 \%$ \\
\hline Asian American/Asian & $2 \%$ & $2 \%$ & $3 \%$ \\
\hline European American/White & $68 \%$ & $73 \%$ & $63 \%$ \\
\hline Latinx & $7 \%$ & $3 \%$ & $7 \%$ \\
\hline Multiracial & $6 \%$ & $2 \%$ & $3 \%$ \\
\hline Native American/American Indian & $2 \%$ & $2 \%$ & $1 \%$ \\
\hline Pacific Islander & $1 \%$ & $0 \%$ & $1 \%$ \\
\hline Unspecified or another ethnicity & $6 \%$ & $11 \%$ & $12 \%$ \\
\hline \multicolumn{4}{|l|}{ Highest Education Level } \\
\hline Less than high school & $2 \%$ & $3 \%$ & $3 \%$ \\
\hline High school diploma or GED & $15 \%$ & $19 \%$ & $23 \%$ \\
\hline Some college & $42 \%$ & $33 \%$ & $38 \%$ \\
\hline 4-Year degree or higher & $24 \%$ & $33 \%$ & $26 \%$ \\
\hline Advanced degree & $16 \%$ & $12 \%$ & $11 \%$ \\
\hline \multicolumn{4}{|l|}{ U.S.-Based Region } \\
\hline Midwest & $14 \%$ & $18 \%$ & $22 \%$ \\
\hline Northeast & $16 \%$ & $21 \%$ & $18 \%$ \\
\hline South & $38 \%$ & $43 \%$ & $38 \%$ \\
\hline West & $22 \%$ & $18 \%$ & $22 \%$ \\
\hline Outside of U.S. & $10 \%$ & $0 \%$ & $0 \%$ \\
\hline \multicolumn{4}{|l|}{ Household Income } \\
\hline$<\$ 20,000$ & $21 \%$ & $16 \%$ & $23 \%$ \\
\hline$\$ 20,000-\$ 49,999$ & $32 \%$ & $39 \%$ & $32 \%$ \\
\hline$\$ 50,000-\$ 99,999$ & $28 \%$ & $33 \%$ & $30 \%$ \\
\hline$>\$ 100,000$ & $10 \%$ & $10 \%$ & $13 \%$ \\
\hline Prefer not to answer & $8 \%$ & $3 \%$ & $2 \%$ \\
\hline Political Orientation & $M=2.74(S D=1.96)$ & $M=3.60(S D=1.78)$ & $M=3.75(S D=1.76)$ \\
\hline
\end{tabular}

Note. Percentages rounded. In Studies 1 and 3, participants rated their political views from

"extremely liberal" (0) to "extremely conservative" (7). In Study 2, participants rated their views from "extremely liberal" (1) to "extremely conservative" (7). 


\section{Study 1}

One challenge for researchers in using extant measurements is the evolution of language as labels become outdated. For example, organizations such as The New York Times (Coleman, 2020) and the APA (2019) discourage the use of non-capitalized "blacks" and "Blacks" as a noun, yet researchers and participants find both embedded throughout popular racism instruments (e.g., Modern Racism Scale; McConahay, 1986). Likewise, homosexual as a label is used in research on sexual prejudice (e.g., homophobia; Haddock et al., 1993; Morrison et al., 1999) and sexual minorities' experiences (e.g., internalized stigma; Mayfield, 2001), though the label may not be one that LGBTQ people would readily use to describe themselves.

Do participants respond to measures differently based on which language is used? We assessed whether sexual minority individuals' self-reported well-being varied as a function of the word "homosexual" in validated psychological instruments-a test of question wording effects (see Smith et al., 2018). We randomly assigned participants to complete measures that included "homosexual" or "lesbian and gay" as a label by changing the wording of scale items. We hypothesized that exposure to the homosexual label would negatively influence participants' reported well-being than when exposed to the LG label.

\section{Method}

An a priori power analysis in $G^{*}$ Power (Faul et al., 2009) recommended 210 participants to detect a medium effect $(d=0.5)$ with $95 \%$ power. We randomly assigned participants to respond to measures that used homosexual language (homosexual label, $n=101$ ) or lesbian/gay language (LG label, $n=105$ ) in the wording of questions. In the homosexual label condition, all measures used the term "homosexual" or "homosexual identity." In the LG label condition, the items used "lesbian/gay" or "lesbian/gay identity." Participants responded to the following: identification with being LGB ( 3 subscales of the Lesbian, Gay, and Bisexual Group Identity Measure; LGB-GIM; Sarno \& Mohr, 2016), positive feelings about being LGB (5 subscales of the Lesbian, Gay, and Bisexual Positive Identity Measure; LGB-PIM; Riggle et al., 2014), self- 
stigma (Revised Internalized Homophobia Scale; IHP-R; Herek et al., 2009), warmth and favorability toward their sexual orientation (single-item thermometer about being homosexual [lesbian/gay]), and perceived closeness (adapted version of the Inclusion of Other in Self Scale; IOS; Aron et al., 1992) between the self and "homosexuals" (or "lesbian/gay people") and between heterosexual people and "homosexuals" (or "lesbian/gay people"). Participants also completed the 20-item Positive and Negative Affect Schedule (Watson et al., 1988).

\section{Results and Discussion}

We conducted independent $t$-tests to examine the label effect on psychological responses. There were no significant differences by condition on the LGB-GIM, three other LGB-PIM subscales, single-item feeling thermometer, perceived closeness, or positive and negative affect; neither age nor gender significantly interacted with condition, all $p$-values > 05 . However, we found a significant effect of condition on three outcomes, but in contrast to the direction of our hypothesis. Compared to the LG label, exposure to the homosexual label caused participants to report greater comfort with their identity ("Authenticity" subscale of the LGB-PIM) $[t(194.70)=2.97, p=.003, d=0.42]$, greater perceived intimacy associated with their identities ("Intimacy" subscale of the LGB-PIM) $[t(199)=2.15, p=.033, d=0.30]$, and less internalized homophobia $[t(194.19)=-2.10, p=.037, d=0.30]$.

Our hypothesis that the homosexual label would negatively influence responses on psychological instruments was unsupported. On three measures (Authenticity and Intimacy subscales of the LGB-PIM and Internalized Homophobia Scale), participants exposed to the homosexual label reported greater authenticity, more intimacy, and lower internalized homophobia than those who viewed LG labeling. One interpretation is that participants who were exposed to homosexual label "reappropriated" the term (Galinsky et al., 2003). In the presence of social identity threat, minoritized individuals may reappropriate stigmatizing labels by reappraising the label into something empowering instead of hurtful (Galinsky et al., 2003; Petriglieri, 2011). That is, people may double down on positive beliefs about their identity in 
response to stigmatizing labels. However, we note that effect sizes were small, the pattern across outcomes was inconsistent, and the internalized homophobia measure evidenced a floor effect. Indeed, across the 14 dependent variables analyzed, a significant difference between conditions was identified on only three outcomes, suggesting that the homosexual label does not carry a drastically negative connotation in this context. We thus interpret the three significant tests with caution. We infer that the homosexual label, when embedded within psychological instruments, likely has no systematic impact on how LG people respond to surveys.

\section{Study 2}

We investigated perceptions of different labels by manipulating the format of a sexual orientation demographic question. Demographic questions in the real-world vary greatly. Some questions provide a variety of answer choices, whereas others are limited to a few response options. In the case of sexual orientation, researchers and institutions tend to rely on outdated, simplistic measures as opposed to more multifaceted, contemporary assessments of sexuality (Salomaa \& Matsick, 2019). As a result, "homosexual" remains a staple response option of demographic instruments across settings, such as in healthcare. We evaluated how LG participants perceived a demographic-type question that included "homosexual" as a label compared to a question that used "lesbian or gay." We also provided a comparison group based on group membership (heterosexual individuals).

Consistent with the SCL effect and group-based differences in vigilance, we hypothesized that labeling would be meaningful, but the effect would vary by group membership. We predicted that heterosexual participants' perceptions of a demographic question would not differ by label; however, the label used would influence LG participants' reactions, such that they would more negatively perceive the demographic question that used homosexual than LG as a label. We also expected that perceiving the question format as culturally competent would mediate the relationship between label and group membership on perceptions of the demographic question. Cultural competence offers a framework for promoting 
respect and inclusion of others, and as previously described, it is a complex construct that can be assessed through judgments about people's attitudes, knowledge and awareness, and skills on display (see Sue, 2001). Here, we focus on one of many aspects of cultural competence by measuring perceived cultural competence as the knowledgeable and skillful inclusion of others.

\section{Method}

\section{Participants}

An a priori power analysis in $\mathrm{G}^{*}$ Power (Faul et al., 2009) recommended 210 participants to detect a medium sized effect $(f=.25)$ with $95 \%$ power. The final sample included 332 participants recruited from paid online survey platforms (e.g., Qualtrics paneling). We identified eligible participants with a demographic screener and excluded participants who did not fit criteria or who generated low quality data (e.g., finished in under 2 minutes). The sample included 56 lesbian women, 58 gay men, 92 heterosexual women, and 119 heterosexual men.

\section{Design and Procedure}

Participants were presented with two questions asking about their sexual orientation: the questions included response options of Homosexual [Lesbian/Gay], Heterosexual, and Bisexual. These questions were only used as experimental materials, not to collect demographic information. Participants reviewed both questions, and then were randomly assigned to provide opinions about one question (homosexual label, $n=166$; LG label, $n=166$ ). We repeated the demographic question to which they were assigned on every survey page. We randomized measures to avoid order effects. At the end of the study, participants completed demographic questions, open-ended questions, and data quality checks.

\section{Materials and Measures}

In Studies 2 and 3, we used several of Broussard et al. (2018)'s measures to assess attitudes toward a demographic question's style (e.g., perceived inclusiveness, format preferences, applied attitudes ratings). Whereas Broussard et al. (2018) focused on an expansive question about gender identity, we focused on a question about sexual orientation. 


\section{Perceived Cultural Competency}

Seven items measured the inclusivity of the question-a quality of cultural competency. Items reflected those used to evaluate perceptions of a gender demographic question as inclusive (Broussard et al., 2018; 1=strongly disagree, 5=strongly agree). Example items included: "I feel like this way of asking about sexual orientation is a modern way of asking people about their identities" and "I feel like this way of asking about sexual orientation will make almost everyone feel included." There was one reverse-scored item. We averaged the items into a scale $(\alpha=.86)$; greater scores indicated more cultural competency.

\section{Format Liking}

Eleven items measured liking of the question (Broussard et al., 2018). Participants responded on a 5-point scale ( $1=$ strongly disagree, $5=$ strongly agree). Example items included: "I like how this question asked about my sexual orientation" and "I think this question is appropriately worded." We reverse-scored four items and averaged items into a scale $(\alpha=.89)$. Greater scores indicated greater liking.

\section{Feeling Thermometer}

We included a feeling thermometer to assess general positivity toward the question. It is possible that one could perceive a question as not being inclusive, but still feel positive about it or could perceive a question as being inclusive but have negative feeling toward it that is not captured by the format liking measure. Participants used a 101-point sliding scale to rate how they felt about how the question asked about their sexual orientation $(0=$ cold and not favorable, $100=$ warm and favorable). We adapted instructions from feeling thermometers used in American National Election Studies (Zavala-Rojas, 2014). Ratings between 0-50 conveyed cold/not favorable feelings, 50-100 conveyed warm/favorable feelings, and the 50-mark indicated that one does not feel particularly warm or cold toward the question.

\section{Applied Attitudes Ratings}


Inspired by Broussard et al. (2018), nine items measured perceptions of educational, health, and employment settings that hypothetically used the demographic question to ask about sexual orientation. In each context (i.e., a school, doctor's office, and workplace), participants answered three questions about how they would feel if the institution used the demographic question ( $1=$ strongly disagree, $5=$ strongly agree). Items included: "I would feel that this [school, doctor's office, workplace] was welcoming to lesbian and gay patients," "I would feel comfortable at this [school, doctor's office, workplace]," and "I would feel that people understand me at this [school, doctor's office, workplace]." We averaged items into three scales: School (3 items; $\alpha=.90$ ), Doctor's Office (3 items; $\alpha=.92$ ), and Workplace (3 items; $\alpha=.94$ ). Higher scores indicated more positive perceptions.

\section{Results and Discussion}

We conducted a two-way MANOVA. We then interpreted follow-up univariate tests and applied a Bonferroni correction. We used simple effects tests to identify the nature of significant interactions, and we tested for moderated mediation. We report confidence intervals of mean differences of simple effects and main effects.

We found an overall significant effect of label [Pillai's trace $=0.05, F(6,322)=2.68, p=.02$, $\eta_{p}^{2}=.05$ ], a significant effect of group membership [Pillai's trace $=0.09, F(6,322)=5.18, p<.001$, $\eta_{p}^{2}=.09$ ], and a significant interaction of label and group membership [Pillai's trace $=0.05, F(6$, $\left.322)=2.85, p=.010, \eta_{p}{ }^{2}=.05\right]$ on cultural competency, liking for the question's format, favorable feeling toward the question, and applied attitudes ratings.

\section{Perceived Cultural Competency}

There was a significant interaction between label and group membership, $F(1$, $327)=10.81, p=.001, \eta_{p}{ }^{2}=.03$. Labels influenced LG people's perceptions of cultural competency $\left[F(1,328)=14.84, p<.001, \eta_{p}^{2}=.04, \mathrm{Cl}_{95}(-0.84,-0.27)\right]$ but not heterosexual people's perceptions, $F(1,328)=0.10, p=.75, \eta_{p}^{2}=.00, \mathrm{Cl}_{95}[-0.18,0.25]$. LG participants viewed the 
homosexual label question to be less culturally competent $(M=3.19, S E=0.10)$ than the LG label question $(M=3.75, S E=0.10)$. We also found a main effect of label, $F(1,327)=8.25, p=.004$, $\eta_{p}^{2}=.03, \mathrm{Cl}_{95}[-0.44,-.08]:$ People in the homosexual label perceived the question to be less culturally competent $(M=3.42, S E=0.06)$ than those who reviewed the LG label $(M=3.68$, $S E=0.06)$. We found no main effect of group membership, $F(1,327)=2.99, p=.09$.

\section{Format Liking}

We found a significant interaction between label and group membership, $F(1$, $327)=15.74, p<.001, \eta_{p}^{2}=.05$. LG participants had less liking for the homosexual label question $(M=3.32, S E=0.09)$ than the LG label $(M=3.91, S E=0.10), F(1,328)=19.45, p<.001, \eta_{p}^{2}=.06, C_{95}$ $[-0.85,-0.33]$. Heterosexual people's liking for the question did not significantly differ by condition, $F(1,328)=0.53, p=.47, \eta_{p}{ }^{2}=.00, C_{95}[-0.12,0.27]$. There was a significant main effect of label, $F(1,327)=9.50, p=.002, \eta_{p}{ }^{2}=.03, \mathrm{Cl}_{95}[-0.42,-0.09]$ : participants liked the homosexual label question ( $M=3.63, S E=0.06)$ less than the $L G$ label question $(M=3.89, S E=0.06)$. We also found a main effect of group membership, $F(1,327)=12.21, p<.001, \eta_{p}^{2}=.04, \mathrm{Cl}_{95}[0.13,0.46]$ : Regardless of the label used, heterosexual participants liked the format more $(M=3.91$, $S E=0.05)$ than $L G$ participants $(M=3.62, S E=0.07)$.

\section{Feeling Thermometer (Favorable Feeling Toward the Question)}

We found a significant interaction between label and group membership, $F(1,327)=6.89$, $p=.009, \eta_{p}^{2}=.02$. LG participants felt less favorably about the homosexual label question $(M=65.98, S E=3.10)$ than the LG label question $(M=77.48, S E=3.13), F(1,327)=6.81, p=.009$, $\eta_{p}^{2}=.02, \mathrm{Cl}_{95}[-20.15,-2.83]$. Heterosexual people's feelings did not differ by label, $F(1$, $327)=0.80, p=.37, \eta_{p}^{2}=.00, \mathrm{Cl}_{95}[-3.54,9.43]$. The main effects of label $[F(1,327)=2.42, p=.12]$ and group membership $[F(1,327)=0.32, p=.57]$ were non-significant.

\section{Applications of the Label Effect in Educational, Health, and Employment Settings}

\section{School}


We found a significant interaction between label and group membership in evaluating a school, $F(1,327)=8.27, p=.004, \eta_{p}^{2}=.03$. LG participants who viewed the homosexual label evaluated the school less positively $(M=3.01, S E=0.13)$ than $L G$ participants in the $L G$ label condition $(M=3.62, S E=0.13), F(1,328)=10.57, p=.001, \eta_{p}^{2}=.03, C_{95}[-0.98,-0.24]$. However, label did not change heterosexual participants' perceptions, $F(1,328)=0.30, p=.58, \eta_{p}{ }^{2}=.00, \mathrm{Cl}_{95}$ $[-0.20,0.35]$. There was a significant main effect of label, $F(1,327)=5.47, p=.02, \eta_{p}{ }^{2}=.02, \mathrm{Cl}_{95}[-$ $0.50,-0.04]$. Participants in the homosexual label condition evaluated the school less positively $(M=3.31, S E=0.08)$ than participants in the $L G$ label condition $(M=3.59, S E=0.08)$. We also found a significant main effect of group membership: Heterosexual participants $(M=3.58$, $S E=0.07)$ evaluated the school more positively than LG participants $(M=3.32, S E=0.09), F(1$, $327)=5.14, p=.02, \eta_{p}^{2}=.02, \mathrm{Cl}_{95}[0.04,0.50]$.

\section{Doctor's Office}

There was a significant interaction between label and group membership in evaluating a doctor's office, $F(1,327)=8.90, p=.003, \eta_{p}{ }^{2}=.03$. LG participants who viewed the homosexual label evaluated the doctor's office less positively $(M=3.21, S E=0.13)$ than those who viewed the LG label $(M=3.72, S E=0.13), F(1,328)=7.44, p=.007, \eta_{p}^{2}=.02, C l_{95}[-0.88,-0.14]$. However, among heterosexual participants, viewing the homosexual or LG label did not change their perceptions, $F(1,328)=1.91, p=.17, \eta_{p}^{2}=.01, \mathrm{Cl}_{95}[-0.08,0.47]$. We found no main effects of label $[F(1,327)=1.90, p=.17]$ or group membership $[F(1,327)=3.17, p=.08]$.

\section{Workplace}

We found a significant interaction between label and group membership in evaluating a potential workplace, $F(1,327)=6.07, p=.01, \eta_{p}{ }^{2}=.02$. LG participants in the homosexual label condition evaluated the workplace less positively $(M=2.85, S E=0.14)$ than $L G$ participants who viewed the LG label $(M=3.30, S E=0.14), F(1,328)=4.98, p=.03, \eta_{p}^{2}=.02, \mathrm{Cl}_{95}[-0.85,-0.05]$. Among heterosexual participants, the labels did not change their perceptions, $F(1,328)=1.58$, 
$p=.21, \eta_{p}^{2}=.01, \mathrm{Cl}_{95}[-0.11,0.49]$. The effect of label was non-significant $[F(1,327)=1.28, p=.26]$, but we found a significant main effect of group membership, $F(1,327)=10.00, p=.002, \eta_{p}^{2}=.03$,

$\mathrm{Cl}_{95}[0.15,0.64]$. Heterosexual participants perceived the workplace more positively $(M=3.47$, $S E=0.08)$ than $L G$ participants $(M=3.08, S E=0.10)$.

\section{Mediational Analysis: Perceived Cultural Competency}

We conducted moderated mediation to examine the indirect effect of label on five outcomes through perceived cultural competency moderated by group membership. This analysis determined whether LG participants' positive impressions of the question (i.e., higher liking, favorable feeling, positive perceptions of three applied contexts) was attributable to perceiving the homosexual label as less culturally competent than the LG label, and whether this effect differed across group membership. Using PROCESS (Hayes, 2017; model 7), we resampled 5,000 times for bootstrapping estimates, and the distribution of the effects was used to obtain $95 \%$ confidence intervals for the size of the indirect effect of culturally competency. We interpreted significance of indirect effects based on whether the index of moderated mediation excluded 0 . We entered label as the independent variable ( $0=$ homosexual label, $1=\mathrm{LG}$ label) and group membership as the moderator $(0=$ heterosexual, $1=\mathrm{LG})$.

Across all five outcomes, indices of moderated mediation of label condition through cultural competency (moderated by group membership) was significant: format liking $[b=.38$, $\mathrm{SE}=0.13, \mathrm{Cl}_{95}=0.15$ to 0.64$]$, favorable feeling toward the question $\left[b=9.86, \mathrm{SE}=3.44, \mathrm{Cl}_{95}=3.60\right.$ to 17.16], positive perceptions of a school $\left[b=0.45, S E=0.15, C_{95}=0.18\right.$ to 0.76$]$, positive perceptions of a doctor's office $\left[b=0.49, \mathrm{SE}=0.17, \mathrm{Cl}_{95}=0.18\right.$ to 0.84$]$, and positive perceptions of a workplace $\left[b=0.44, \mathrm{SE}=0.15, \mathrm{Cl}_{95}=0.18\right.$ to 0.76$]$. In all tests, the homosexual label compared to the LG label was perceived as less culturally competent by LG people, which partially explained the relationship between the label and LG participants' positive perceptions. All indirect effects among heterosexual participants were non-significant. See Figures 1-2. 


\section{Figure 1}

Mediating Role of Perceived Cultural Competency in the Effect of Label (Moderated by Group Membership) on Positive Perceptions of the Question (Study 2)

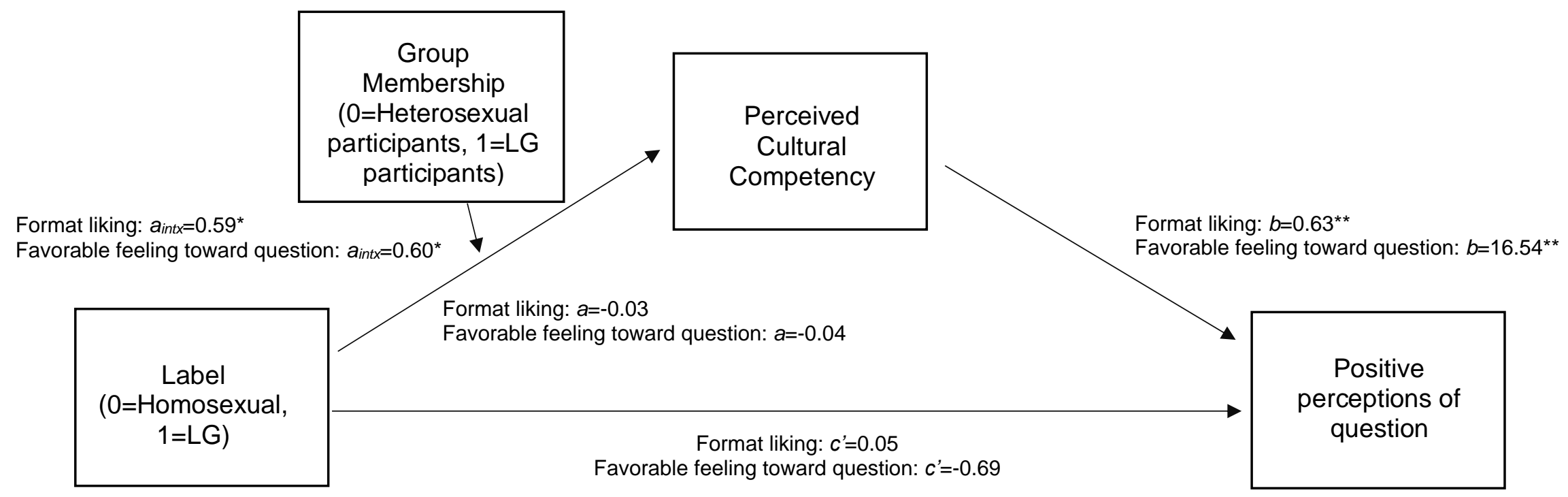

Note. Results revealed a significant difference in the mediated pathway between group membership, indicated by the indices of moderated mediation. The indirect effect among LG participants was $0.35, \mathrm{Cl}_{95}[0.17,0.57]$ (DV: Format liking) and 9.24, $\mathrm{Cl}_{95}[4.30,14.94]$ (DV: Favorable feelings toward the question). The indirect effect among heterosexual participants was $-0.02, \mathrm{Cl}_{95}[-0.16,0.11]$ (DV: Format liking) and $-0.62, \mathrm{Cl}_{95}[-4.57,2.73]$ (DV: Favorable feelings toward the question). Unstandardized beta coefficients are reported. ${ }^{*} p<.05 .{ }^{* *} p<.001$. 


\section{Figure 2}

Mediating Role of Perceived Cultural Competency in the Effect of Label (Moderated by Group Membership) on Positive Perceptions of Institutions (Study 2)

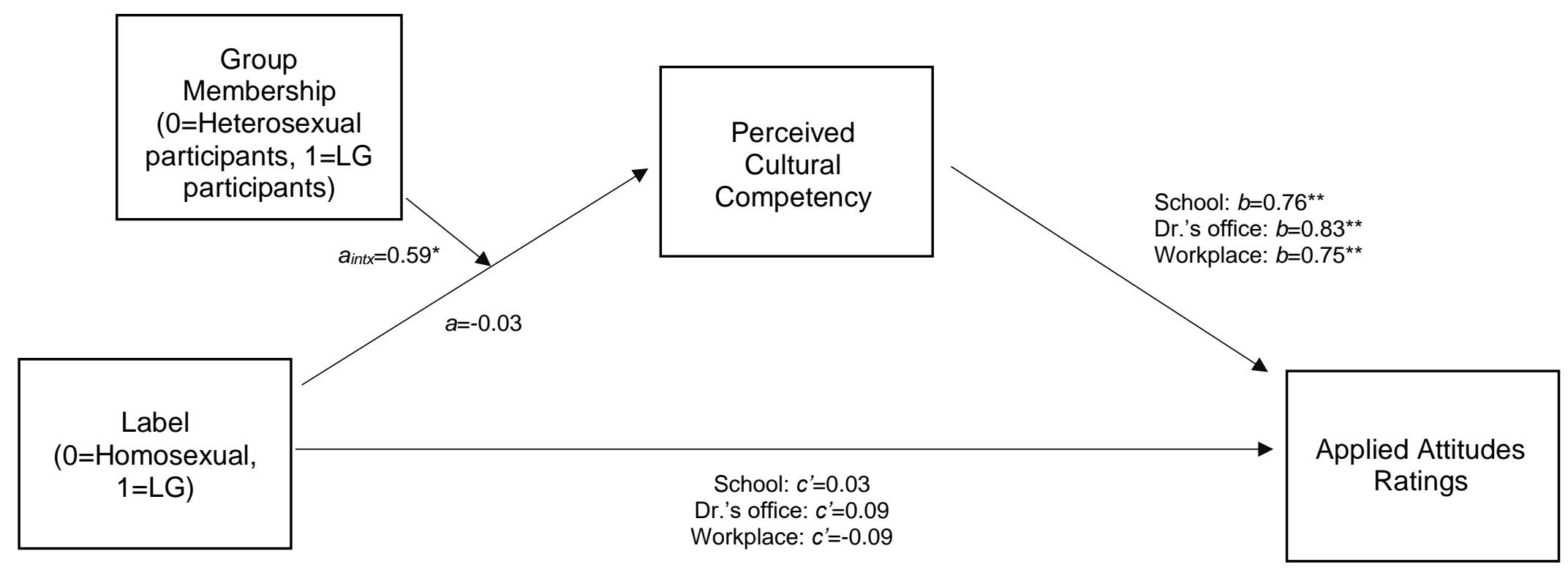

Note. Results revealed a significant difference in the mediated pathway between group membership, indicated by the indices of moderated mediation. The indirect effect among LG participants was 0.42, $\mathrm{Cl}_{95}$ [0.21, 0.68] (DV: School), 0.46, $\mathrm{Cl}_{95}[0.21,0.74]$ (DV: Doctor's office), and 0.42, $\mathrm{Cl}_{95}[0.19,0.67]$ (DV: Workplace). The indirect effect among heterosexual participants was -0.03, $\mathrm{Cl}_{95}[-0.19,0.14]$ (DV: School), 0.09, $\mathrm{Cl}_{95}[-0.21,0.14]$ (DV: Doctor's office), and -0.03, Cl95 [-0.19, $0.13]$ (DV: Workplace). Unstandardized beta coefficients are reported. ${ }^{*} p<.05 .{ }^{* *} p<.001$. 


\section{Results Summary}

Results supported our hypothesis that the SCL effect depends on group membership. LG people perceived a demographic question to be less culturally competent, likeable, and favorable when the question used a homosexual label compared to a LG label. Heterosexual people's perceptions were largely unaffected by label use. We also found that labeling had consequences for LG people's impressions of institutions attached to those questions. Across

all contexts (education, health, employment), LG participants believed that institutions using the homosexual label would be less welcoming, comfortable, and understanding than institutions using the LG label. We confirmed the mediating role of perceived cultural competency on all outcomes, and these indirect effects were only significant among LG participants. LG participants reported more negative perceptions of the homosexual label question compared to the LG label question because they perceived the homosexual label question as less culturally competent. We return to discussion of Study 2's findings in our General Discussion.

\section{Study 3}

We tested LG and heterosexual people's reactions to the homosexual label in a personperception paradigm. We randomly assigned participants to view a text message exchange in which a target either used "homosexuals" or "lesbian and gay people" to describe their coworkers. Participants evaluated the target. We adopted Study 2's hypotheses: (1) the label effect would depend on group membership, and (2) among LG participants, perceived cultural competency would mediate the relationship between label use and perceptions of the user. To expand what may be expected of cultural competence, we focused on the likelihood that a target would enact behaviors that are supportive and affirming through activism and advocating. That is, as noted by multidimensional models of cultural competence (Danso, 2018; Goodman, 2020; Ridley et al., 2001; Sue, 2001), cultural competence not only involves cultural awareness and knowledge for training, but also sociopolitical behavior toward anti-oppression and social justice. We thus focus this study on an aspect of cultural competence that was left unaddressed 
by Study 2 by now measuring perceived cultural competence as the commitment to social justice, allyship, and advocacy.

\section{Method}

\section{Participants}

We used Study 2's sampling procedures. The final sample $(N=296)$ included 74 lesbian women, 73 gay men, 73 heterosexual women, and 73 heterosexual men. Prior to analysis, three participants were removed for dropping out of the study.

\section{Design and Procedure}

We followed similar procedures as in Study 2. We told participants that we were interested in first impressions of people and randomly assigned them to read one of two text message conversations: a conversation in which the target used the word "homosexuals" (homosexual label, $n=140$ ) or used the phrase "lesbian and gay people" (LG label, $n=153$ ).

\section{Materials and Measures}

To establish the person-perception paradigm, we created text message conversations between two coworkers in iMessage. Participants evaluated the person whose comments were displayed by gray text boxes on the left side of the text message. In the conversation, the target declined a co-worker's offer for lunch because they had a diversity workshop to attend. When asked why the diversity workshop was happening, the target said: "I think it's because so many of our coworkers are lesbian and gay [homosexuals]." Both text conversations were identical, save for the category label.

\section{Perceived Cultural Competency}

We assessed the extent to which participants believed that the target would act in culturally competent and supportive ways, using themes found in research on heterosexual allies. Participants responded to eight items on a 7-point scale (1=extremely unlikely, 7=extremely likely; $\alpha=.79$; Fingerhut, 2011). Example items included, "How likely is this person to initiate discussions promoting lesbian and gay rights?" and "How likely is this person to 
support a sibling that came out as lesbian or gay?" We averaged items into a scale $(\alpha=.98)$.

Greater scores indicated greater cultural competency.

\section{Personal Characteristics}

We included 14 semantic-differentials to measure participants' evaluation of the target on a variety of characteristics: "trustworthy/untrustworthy," "unlikeable/likable," "friendly/unfriendly," "liberal/conservative," "open-minded/close-minded," "oldfashioned/modern," "prejudiced/non-prejudiced," "young/old," "warm/cold," “informed/uninformed," "unaccepting/accepting," "safe/unsafe," "intolerant/tolerant," and “competent/incompetent.” Participants responded on 6-point scales. We were primarily interested in perceptions of the target as appearing prejudiced; thus, we focused on the following items: "open-minded/close-minded," "prejudiced/non-prejudiced,"

“informed/uninformed," "unaccepting/accepting," "safe/unsafe," and "intolerant/tolerant." Electronic supplemental material provides descriptive information.

\section{Social Distance}

Seven items measured desired amount of social distance between oneself and the target of the text message conversation (Liekens et al., 2012; Link et al., 1987). For example, we asked, "How would you feel about sharing an apartment with someone like them?" and "How would you feel like recommending a job for someone like them?" We made minor wording changes (e.g., "flat" replaced with "apartment"). Participants responded on a 4-point scale (1=definitely unwilling, $4=$ definitely willing). The scale had good reliability $(\alpha=.96$; prior research reported $\alpha=.91-.92$; Liekens et al., 2012; Link et al., 1987). One participant answered only one of the seven items; therefore, their data were not used in analyses using this scale. We calculated a social distance total score by summing the seven items, which resulted in scores from 7 to $28(M=17.03, S D=6.17)$. Lower values indicated more desire for social distance, whereas greater values indicated more willingness for social closeness.

\section{Applied Attitudes Ratings}


Similar to Study 1, 9 items measured perceptions of educational, health, and employment settings by inquiring about perceptions of hypothetical professionals in each setting. Participants answered three questions about how they would feel if the target was the participant's teacher, doctor, or coworker. Participants responded on a 5-point scale $(1=$ strongly disagree, 5=strongly agree). Items included: "I would feel that this [teacher, doctor, coworker] was welcoming," "I would feel comfortable with this [teacher, doctor, coworker]," and "I would feel that this [teacher, doctor, coworker] would understand me." We averaged the items into scales: Teacher (3 items; $\alpha=.95$ ), Doctor (3 items; $\alpha=.94$ ), and Coworker (3 items; $\alpha=.95$ ). Greater scores reflected more positive perceptions of the professional.

\section{Results and Discussion}

Following Study 2's analytical procedures, we found an overall significant effect of label [Pillai's trace $=0.08, F(11,278)=2.06, p=.02, \eta_{p}^{2}=.08$ ] on cultural competency, the 6 personal characteristics, social distance, and the applied attitudes ratings. The effect of group membership [Pillai's trace $=0.05, F(11,278)=1.36, p=.19$ ] and interaction of label and group membership [Pillai's trace $=0.03, F(11,278)=0.69, p=.75]$ were non-significant.

\section{Perceived Cultural Competency}

We found a significant main effect of label on cultural competency, $F(1,288)=6.85$, $p=.009, \eta_{p}^{2}=.02, C_{95}[-0.90,-0.13]$. Participants perceived the homosexual label user as less culturally competent $(M=3.14, S E=0.14)$ than the $L G$ label user $(M=3.65, S E=0.14)$. The main effect of group membership $[F(1,288)=0.00, p=.96]$ and the interaction between label and group membership $[F(1,288)=0.02, p=.89]$ were non-significant.

\section{Personal Characteristics}

There was a significant label effect on four personal characteristics. The homosexual label user was perceived as more closeminded $(M=3.93, S E=0.14)$ than the $L G$ label user $(M=3.43, S E=0.13), F(1,288)=7.24, p=.008, \eta_{p}^{2}=.03, C l_{95}[0.14,0.87]$. Participants perceived 
the homosexual label user as more uninformed $(M=3.81, S E=0.14)$ than the $L G$ label user $(M=3.32, S E=0.13), F(1,288)=6.64, p=.01, \eta_{p}^{2}=.02, C l_{95}[0.12,0.86]$. The homosexual label user was seen as being less accepting $(M=3.07, S E=0.14)$ than $L G$ label user $(M=3.73$, $S E=0.13), F(1,288)=12.08, p<.001, \eta_{p}^{2}=.04, \mathrm{Cl}_{95}[-1.02,-0.28]$, and as less tolerant $(M=3.21$, $S E=0.13)$ than the LG label user $(M=3.75, S E=0.12), F(1,288)=9.20, p=.003, \eta_{p}^{2}=.03, \mathrm{Cl}_{95}[-$ $0.90,-0.19]$. There were no significant effects of label on perceptions of the target as nonprejudiced $[F(1,288)=0.72, p=.40]$ and unsafe $[F(1,288)=3.18, p=.08]$.

There were no significant effects of group membership ( $p$-values $>.05$ ), except on perceptions of the target as unsafe. LG participants rated targets as more unsafe $(M=3.50$, $S E=0.12)$ than heterosexual participants $(M=3.10, S E=0.12), F(1,288)=5.40, p=.02, \eta_{p}^{2}=.02$, $\mathrm{Cl}_{95}[-0.73,-0.06]$. The interactions of label and group membership were non-significant $(p-$ values $>.05)$.

\section{Social Distance}

There was a significant main effect of label, $F(1,288)=4.27, p=.04, \eta_{p}^{2}=.02, \mathrm{Cl}_{95}[-2.91$, 0.07]. Participants expressed less willingness to be socially close to the homosexual label user $(M=16.26, S E=0.52)$ than to the $L G$ label user $(M=17.75, S E=0.50)$. The main effect of group membership $[F(1,288)=0.00, p=.95]$ and interaction between label and group membership $[F(1$, 288) $=0.17, p=.69]$ were non-significant.

\section{Applications of Homosexual Label Effect to Ratings of Professionals}

\section{Teacher}

The effect of label $[F(1,288)=3.84, p=.05]$, group membership $[F(1,288)=1.27, p=.26]$, and interaction between label and group membership $[F(1,288)=0.02, p=.90]$ were nonsignificant.

\section{Doctor}


The effect of label $[F(1,288)=2.28, p=.13]$, group membership $[F(1,288)=2.65, p=.11]$, and interaction between label and group membership $[F(1,288)=0.16, p=.69]$ were nonsignificant.

\section{Coworker}

There was a significant main effect of label, $F(1,288)=6.65, p=.01, \eta_{p}^{2}=.02, C l_{95}[-0.61$, 0.08]: Participants expressed that they would feel less welcomed, comfortable, and understood by the homosexual label user $(M=2.80, S E=0.10)$ than the $L G$ label user $(M=3.14, S E=0.09)$. There was no main effect of group membership $[F(1,288)=3.11, p=.08]$ nor an interaction between label and group membership, $F(1,288)=0.04, p=.84$.

\section{Mediational Analysis: Perceived Cultural Competency}

We tested the indirect effect of label use on six outcomes through perceived cultural competence. Following similar procedures as Study 2, we used bootstrapped mediation analysis with PROCESS (Hayes, 2017; Model 4) to examine the indirect effect of label use on desired social distance from the target, positive perceptions of the target as a coworker, and perceptions of the target as closeminded, uninformed, accepting, and tolerant. The indirect effect of label use ( $0=$ homosexual label, $1=\mathrm{LG}$ label) through perceived cultural competence was significant on all outcomes: social distance, $b_{\text {indirect }}=1.14, S E=0.46, C_{95}[0.23,2.04]$, positive perceptions of the target as a coworker, $b_{\text {indirect }}=0.21, S E=0.09, \mathrm{Cl}_{95}[0.05,0.39]$, and perceptions of the target as closeminded, $b_{\text {indirect }}=-0.29, S E=0.12, C_{95}[-0.53,-0.06]$, uninformed, $b_{\text {indirect }}=-0.27, S E=0.11, \mathrm{Cl}_{95}[-0.50,-0.05]$, accepting, $b_{\text {indirect }}=0.28, S E=0.11, \mathrm{Cl}_{95}[0.07,0.50]$, and tolerant, $b_{\text {indirect }}=0.20, S E=0.08, \mathrm{Cl}_{95}[0.04,0.38]$. In all tests, people rated the homosexual label user as less culturally competent, which accounted for less positive perceptions of a coworker, lower perceptions of the target as tolerant and accepting, greater desired social distance from the target, and greater perception of the target as uninformed and closeminded. The indirect effects among heterosexual participants were non-significant; whereas, the indirect effects among LG participants were significant across the five outcomes. See Figures 3-5. 


\section{Figure 3}

Mediating Role of Perceived Cultural Competency in the Effect of Label on Desired Social Distance from Target (Study 3)

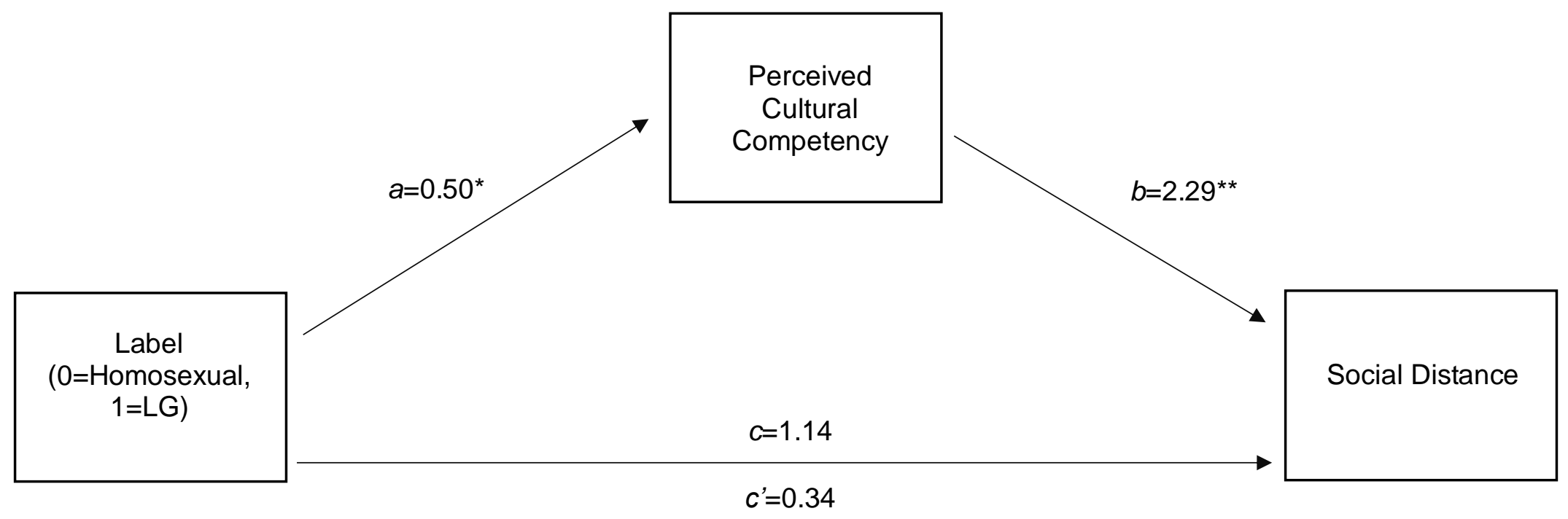

Note. Unstandardized beta coefficients are reported. ${ }^{*} p<.05 .{ }^{* \star} p<.001$. 


\section{Figure 4}

Mediating Role of Perceived Cultural Competency in the Effect of Label on Positive Perceptions of a Coworker (Study 3)

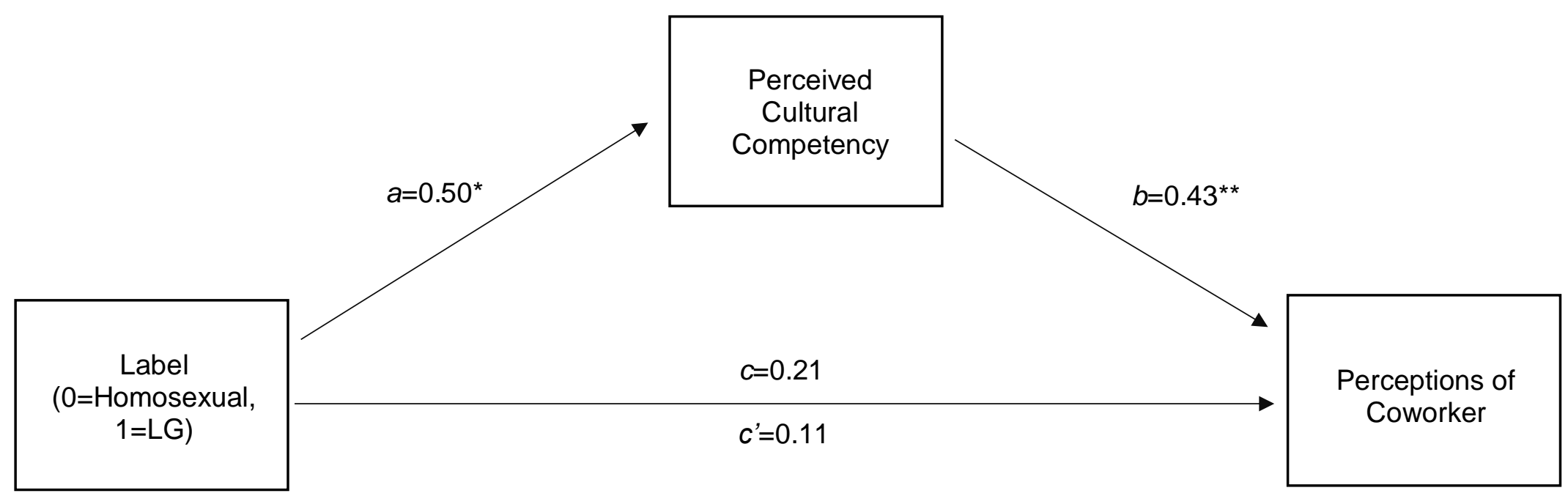

Note. Unstandardized beta coefficients are reported. ${ }^{*} p<.05 .{ }^{* *} p<.001$. 


\section{Figure 5}

Mediating Role of Perceived Cultural Competency in the Effect of Label on Personal Characteristics (Study 3)

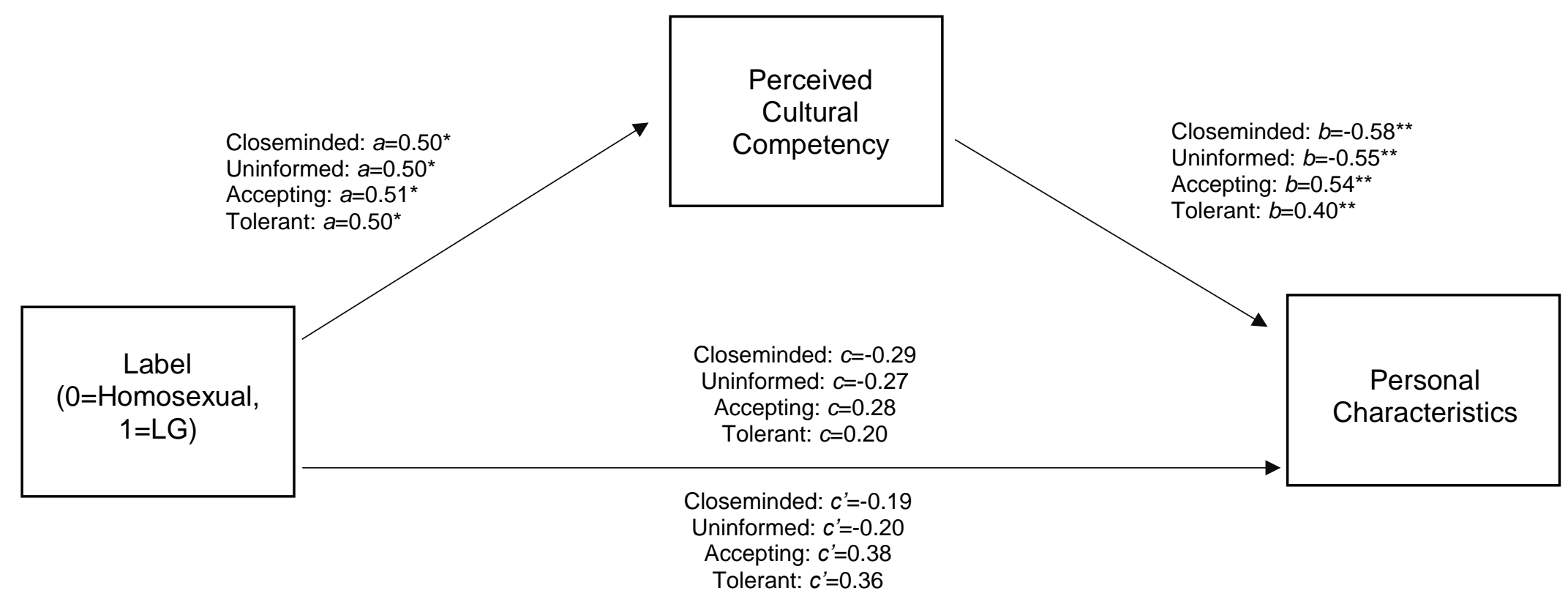

Note. Unstandardized beta coefficients are reported. ${ }^{*} p<.05 .{ }^{* *} p<.001$. 


\section{Results Summary}

Participants reported more negative reactions to someone who used the homosexual label than the LG label; however, our hypothesis that this effect would depend on group membership was unsupported. Both LG and heterosexual participants thought that the target who used the homosexual label would be less culturally competent, and this partially explained their reactions (e.g., less willingness to be socially close to the target, more negative perceptions of the target in a workplace). Although the label effect applied to perceptions of the target as a coworker, it did not influence perceptions of a teacher $(p=.05)$ or doctor. These findings yielded a perplexing inconsistency. Why would different SCLs impact the evaluation of coworkers but not teachers or doctors? It is possible that participants imagine a more frequent, interdependent relationship with a coworker than with a doctor or a teacher, thus may be more hesitant to overlook potentially inappropriate or problematic behaviors of a coworker. We also surmise that the target casted as a teacher or doctor might have implied more professional and high-status roles. It may be more difficult to imagine teachers and doctors (i.e., respected, mature professionals) engaging in such casual text exchanges than it is to observe coworkers (i.e., peers) doing so. If the act of texting among teachers and doctors is perceived as "breaking character" for their positions, the text exchange may have distracted participants and the label effect may have been lessened. It may also be the case that participants expect a standard level of competency from teachers and doctors; These members of the community are held in high esteem. Therefore, subtle cues in a one-time exchange may have little impact on how people evaluate those professionals.

\section{General Discussion}

We examined different contexts of everyday life in which the "homosexual" label may contribute to LG people's well-being. Study 1 tested the SCL effect's application to commonly used psychological measures; Results suggested that, at least in the case of the homosexual label, labeling does not reliably interfere with reporting via extant measures. Exposure to the 
homosexual label did not consistently impact sexual minorities' well-being scores. We did not find support for the SCL effect, and among three outcomes, labeling influenced responses in the opposite direction than expected, though we cautiously interpret these findings. We conclude that Study 1 offers some promising news for the anticipated longevity of scales: Labels within survey instruments did not consistently alter scores on psychological measures, and we found little support for question wording effects.

In Study 2, we examined reactions to labels within demographic questions. LG participants reported more negative reactions to demographic questions (and attached institutions) when the question used the homosexual label rather than the LG label. In contrast, label use did not significantly shape heterosexual participants' responses. We interpret the interaction between label use and group membership in light of the privileged standpoint of heterosexual people. Heterosexual people are not as accustomed to thinking about their sexualities as sexual minorities are-a privilege of belonging to a dominant, prototypical group of social categories (Abed et al., 2019; Case et al., 2012; Pratto \& Stewart, 2012). There is less need for heterosexual people to be vigilant to sexual orientation labeling. By belonging to the privileged group, heterosexual individuals may be unaware of how seemingly trivial labeling practices can serve as cues, and they also may lack knowledge of the sociohistorical challenges encountered by sexual and gender diverse individuals thus overlooking the use of stigmatizing labels (López-Sáez et al., 2021). It is possible that heterosexual participants across Studies 2 and 3 differed in their knowledge and awareness of LGBTQ+ people's experiences, with Study 3's heterosexual participants being more allied with LGBTQ+ communities and more aware of issues surrounding sexual and gender diversity. In addition, heterosexual people generally fit into institutions based on their sexual orientation; They perceived hypothetical settings as more positive (e.g., welcoming) than LG people. Though some heterosexual people may express belonging concerns in workplaces or healthcare settings (e.g., due to race or gender), sexual orientation is not determinant of their belonging; therefore, they may be less attuned to labels 
that promote sexual stigma in those environments. Overall, the standpoint of dominant groups does not require them to survey their environments for safety information, which may explain why heterosexual people's reactions were less affected by Study 2's label manipulation.

However, Study 3 tested whether a target's label use influenced evaluations of them in a modern interpersonal paradigm (a texting scenario). Contrary to Study 2's results, the SCL effect did not depend on group membership: LG and heterosexual participants reported more negative perceptions of the target who used the homosexual label than the LG label. For example, participants perceived the target who used the homosexual label as less accepting and more closed-minded than the LG label user, and desired more social distance from the homosexual label user. It is possible that heterosexual participants were more attentive to the language cue in an interpersonal exchange (Study 3) than in an institutional setting (Study 2) because people with privilege may have an easier time recognizing personally-mediated (e.g., interpersonal) forms of discrimination than institutionalized sources (see Jones, 2000). Put simply, the demographic questionnaire may have been a subtler cue-one that goes undetected by those not sensitive to it-than the dialogue. Because of their unique standpoint as potential targets of stigma, members of minoritized groups are better positioned to detect cues that dominant groups miss (e.g., Inzlicht \& Ben-Zeev, 2000).

Though we recognize some inconsistences across findings, these results are nevertheless informative and should inspire future research on threat and safety cues in language. We emphasize that these studies each test a different context and do not serve as direct replications of each other. The contexts in which we studied the label effect became increasing interpersonal, from understanding perceptions of labels used in a survey setting to a conversational exchange; therefore, it is not completely surprising that the SCL operates somewhat differently in different contexts. Indeed, these results reveal ripe opportunities for further studying relevant boundaries of the SCL effect. Taken the findings together, we are of the position that the word "homosexual" poses little threat for psychometric purposes in survey 
instruments, but it is detected by lesbian and gay individuals (and sometimes heterosexual people, as in Study 3) when used by individuals and institutions. All new evidence considered, we echo previous recommendations to avoid the homosexual label when possible, and we point to the findings of Studies 2-3 as justification for doing so.

\section{Future Directions and Implications: Extending the SCL Effect and Investigating Sexual Orientation-Based Cues}

We promote the idea of incremental science, especially in service of studying the perspectives of hard-to-reach and understudied populations. These three studies serve as a foundation to advance the SCL effect. We extended the SCL effect by examining a stigmatized group's response to different labels, by considering the downstream consequences of labels (e.g., in applied settings), and through evaluating group membership. Our findings support a conceptual broadening of how the SCL operates and for whom. Results confirm that stigmatized groups are attentive to the labels others use to describe them, and they use this information to draw conclusions about others' beliefs about them. The mediational analyses also provided important implications. Labels signal a label user's cultural competency in both institutional (Study 2) and interpersonal (Study 3) contexts. Both LG (Studies 2-3) and heterosexual (Study 3) participants perceived the homosexual label user as less culturally competent. We recognize potential problems with conducting mediational analyses with variables collected at the same time (e.g., potential for bidirectionality). However, our proposed direction was informed from relevant literature (e.g., Cipollina \& Sanchez, 2020), makes practical sense, and supports the model. We would encourage future researchers to continue to expand the construct of cultural competence and what it may encompass (e.g., knowledge, behavior, communication) in making sense of labeling effects. In Study 3, the reliability for cultural competence (a measure of likelihood of activism) was very high, perhaps indicating that this measure captures great specificity or includes redundant items (though interitem correlations were reasonable). In addition, it would also be interesting to consider intent's role in labeling and perceived cultural 
competency, such as whether the target is knowledgeable versus unaware of the label's potentially harmful use. Overall, we argue that cultural competence is not only something that people (e.g., health practitioners) enact but a characteristic that is perceived by others. Specifically, perceptions of cultural competence can be a part of how stigmatized groups make judgments about the contexts they navigate (e.g., asking "Are the people in this space culturally competent? In turn, do I feel safe here?"). Though practically important, cultural competence creates somewhat of a challenge for researchers as there are many ways in which people may arrive to their conclusions about others' cultural competence given that cultural competence is a multidimensional and complex construct. We look forward to continued growth in this area as we believe perceived cultural competence can be useful to understand stigmatized groups' interpretations of their environment.

We also hope this research emboldens future researchers to prioritize the perspectives of stigmatized groups in the SCL effect. The classic tradition in previous testing of the social category effect was to understand how labels could impact intergroup attitudes — an important enterprise for prejudice reduction. However, our approach reveals another benefit to adopting appropriate category labels: It improves well-being and lessens anticipated stigma among targeted groups.

Finally, for sexual minorities, certain words can be pathologizing or stigmatizing without being explicit (e.g., derogatory slurs). LG people consistently expressed more negative reactions to the label "homosexual" versus the phrase "lesbian and gay people." Similar to the concept of linguistic sexism (Gabriel \& Gygax, 2016), we propose the notion of linguistic heterosexism. Connecting linguistic bias to cues research with a special emphasis on sexual minorities presents an exciting future area of research. As we demonstrate, sexual minorities detect threat (or safety) in linguistic patterns and use this information to judge institutions and individuals. This research makes a novel contribution to the literature given that sexual orientation has been mostly overlooked in the cues literature thus far (cf. Cipollina \& Sanchez, 
2021; Matsick et al., 2020). We propose that efforts to create more welcoming and inclusive environments for sexual and gender minorities may in turn create safer environments for everyone (for greater discussion of the possibilities of safety cue transference, see Chaney \& Sanchez, 2018; Chaney et al., 2016).

\section{Generalizability Constraints and Limitations}

Current findings are only generalizable to LG individuals and not all stigmatized groups. Though this work extends the cues literature to sexual orientation, we recognize the limits to generalizability related to other sexual and gender minority identities. We focused on LG people because the history of the word "homosexual" targeted same-gender desire and these two groups emerged as a proxy for homosexual behavior in the 1960s. However, this history partly stems from the erasure of other sexual minority identities (e.g., bisexual). How a broader grouping of sexual minorities respond to homosexual labeling is beyond the scope of these data, but a critical direction for future research to incorporate more balanced sampling across groups who vary across sexual orientation. Further, it is worth noting that some of the items in Studies 2 and 3 included the phrasing "lesbian and gay" which could have signaled to participants that "lesbian and gay" is the appropriate terminology to use. This could not be avoided in some cases (e.g., when the item referred to specific people, like "lesbian and gay people") but, given this language only occurred in very few instances (not across all measures of Studies 2-3) and items and scales were counterbalanced to avoid order effects, it is unlikely that this phrasing significantly impacted the pattern of results. Another limit to generalizability involves queer people of color. Identity labels vary across racial and ethnic communities (Parks, 2001); Our centering of "homosexual", "lesbian", and "gay" most aligns with categories created, used, and challenged by White people (62-73\% of current samples), but less so with other groups (e.g., Black individuals who reject identification with "gay;" Truong et al., 2016). In sum, generalizability is constrained to the word "homosexual," among LG people, and not representative of the diversity of experiences within sexual minority communities. 
We acknowledge that we engaged most with Western perspectives and norms surrounding sexual orientation, cultural competency, and stigma; from theorizing to sampling, our approaches to testing this SCL effect emerged from within a U.S.-specific context. Thus, the findings, as with most psychological insights, are culturally specific and should be interpreted as such. SCL effects are likely bounded by cultural contexts given the inextricable relationship between language and society. For example, language use in one culture can carry a different meaning than in another given differing sociopolitical histories, which would have implications for the robustness of the SCL effect. That is, within other (non-U.S.) cultural contexts, lesbian and gay people may not consider the labeling of "homosexual" as negatively or as outdated as we observed in Studies 2-3. People's sensitivity to SCLs likely depends on the norms in a specific country. Indeed, a promising and innovative future direction would be to test the SCL effect across cultural contexts in light of different metrics of LGBTQ+ people's quality of life (e.g., public attitudes toward LGBTQ+ people, LGBTQ+ rights, the power of various political parties). Until then, we encourage readers to interpret these results as belonging to the cultural context in which they transpired.

\section{Conclusion}

Despite decades worth of recommendations to avoid "homosexual" as a label, such terminology continues to materialize in mainstream discourse (e.g., research, medicine, media, politics). By centering the perspectives and experiences of sexual minorities, we learned that those targeted by the homosexual label are both attentive to labeling choices and use labels to draw conclusions about individuals and environments. If members of dominant groups wish to create welcoming environments for minoritized individuals and to present themselves as being culturally competent, it is in everyone's best interest to avoid labels that imply stigma. 


\section{References}

Abed, E. C., Schudson, Z. C., Gunther, O. D., Beischel, W. J., \& van Anders, S. M. (2019). Sexual and gender diversity among sexual and gender/sex majorities: Insights via sexual configurations theory. Archives of Sexual Behavior, 48(5), 1423-1441. https://doi.org/10.1007/s10508-018-1340-2

Allport, G. W. (1954). The nature of prejudice. Addison-Wesley.

American Psychological Association, APA (2019). Publication manual of the American Psychological Association (7 $7^{\text {th }}$ Ed.). American Psychological Association.

Aron, A., Aron, E. N., \& Smollan, D. (1992). Inclusion of other in the self scale and the structure of interpersonal closeness. Journal of Personality and Social Psychology, 63(4), 596612. https://doi.org/10.1037/0022-3514.63.4.596

Bailey, A. H., LaFrance, M., \& Dovidio, J. F. (2019). Is man the measure of all things? A social cognitive account of androcentrism. Personality and Social Psychology Review, 23(4), 307-331. https://doi.org/10.1177/1088868318782848

Baker, S. J., \& Lucas, K. (2017). Is it safe to bring myself to work? Understanding LGBTQ experiences of workplace dignity. Canadian Journal of Administrative Sciences, 34, 133148. https://doi.org/10.1002/cjas.1439

Bem, S. L., \& Bem, D. B. (1973). Does sex-biased job advertising “aid and abet" sex discrimination? Journal of Applied Social Psychology, 3(1), 6-18. https://doi.org/10.1111/j.1559-1816.1973.tb01290.x

Botelho, M. J., \& Lima, C. A. (2020). From cultural competence to cultural respect: A critical review of six models. Journal of Nursing Education, 59(6), 311-318. https://doi.org/10.3928/01484834-20200520-03

Brewer, M. B. (1988). A dual process model of impression formation. In K. Srull \& S. Wyer (Eds.), Advances in social cognition (Vol. 1, pp. 1-36). Lawrence Erlbaum Associates. 
Brewer, M. B. (2007). The social psychology of intergroup relations: Social categorization, ingroup bias, and outgroup prejudice. In A. W. Kruglanski \& E. T. Higgins (Eds.), Social psychology: Handbook of basic principles (pp. 695-715). The Guilford Press.

Brooks, V. R. (1981). Minority stress and lesbian women. Lexington Books.

Broussard, K. A., Warner, R. H., \& Pope, A. R. D. (2018). Too many boxes, or not enough? Preferences for how we ask about gender in cisgender, LGB, and gender-diverse samples. Sex Roles, 78(9-10), 606-624. https://doi.org/10.1007/s11199-017-0823-2

Carnaghi, A., \& Maass, A. (2007). In-group and out-group perspectives in the use of derogatory group labels: Gay versus fag. Journal of Language and Social Psychology, 26(2), 142156. https://doi.org/10.1177/0261927X07300077

Case, K. A., luzzini, J., \& Hopkins, M. (2012). Systems of privilege: Intersections, awareness, and implications. Social Issues, 68(1), 1-10. https://doi.org/10.1111/j.15404560.2011.01732.x.

Chaney, K. E., \& Sanchez, D. T. (2018). Gender-inclusive bathrooms signal fairness across identity dimensions. Social Psychological and Personality Science, 9(2), 245-253. https://doi.org/10.1177/1948550617737601

Chaney, K. E., Sanchez, D. T., \& Remedios, J. D. (2016). Organizational identity safety cue transfers. Personality and Social Psychology Bulletin, 42(11), 1564-1576. https://doi.org/10.1177/0146167216665096

Cipollina, R., \& Sanchez, D. T. (2021). Identity cues influence sexual minorities' anticipated treatment and disclosure intentions in healthcare settings: Exploring a multiple pathway model. Journal of Health Psychology. https://doi.org/10.1177/1359105321995984

Coleman, N. (2020, July 5). Why we're capitalizing Black. The New York Times. https://www.nytimes.com/2020/07/05/insider/capitalized-black.html Committee on Lesbian and Gay Concerns (1991). Avoiding heterosexist bias in language. American Psychological Association. https://www.apa.org/pi/lgbt/resources/language 
Crawford, J. T., Brandt, M. J., Inbar, Y., \& Mallinas, S. R. (2016). Right-wing authoritarianism predicts prejudice equally toward "gay men and lesbians" and "homosexuals." Journal of Personality and Social Psychology, 111(2), e31-e45. https://doi.org/10.1037/pspp0000070

Danso, R. (2018). Cultural competence and cultural humility: A critical reflection on key cultural diversity concepts. Journal of Social Work, 18(4), 410-430. https://doi.org/10.1177/1468017316654341

Faul, F., Erdfelder, E., Buchner, A., \& Lang, A. G. (2009). Statistical power analyses using G*Power 3.1: Tests for correlation and regression analyses. Behavior Research Methods, 41, 1149-1160. https://doi.org/10.3758/BRM.41.4.1149

Fingerhut, A. W. (2011). Straight allies: What predicts heterosexuals' alliance with the LGBT community? Journal of Applied Social Psychology, 41(9), 2230-2248. https://doi.org/10.1111/j.1559-1816.2011.00807.x

Gabriel, U., \& Gygax, P. (2016). Gender and linguistic sexism. In H. Giles \& A. Maass (Eds., Vol. 21), Language as social action: Advances in intergroup communication (pp. 177192). Peter Lang Publishing.

Galinsky, A. D., Hugenberg, K., Groom, C., \& Bodenhausen, G. (2003). The reappropriation of stigmatizing labels: Implications for social identity. In M. A. Neale \& E. A. Mannix (Series Eds.) \& J. T. Polzer (Ed., Vol. 5), Research on managing groups and teams: Identity issues in groups (pp. 221-256). Emerald Group.

Galinsky, A. D., Wang, C. S., Whitson, J. A., Anicich, E. M., Hugenberg, K., \& Bodenhausen, G. V. (2013). The reappropriation of stigmatizing labels: The reciprocal relationship between power and self-labeling. Psychological Science, 24(10), 2020-2029. https://doi.org/10.1177/0956797613482943

Gay and Lesbian Alliance Against Defamation, GLAAD (n.d.). Media Reference Guide. https://www.glaad.org/reference/offensive 
Goodman, D. J. (2020). Cultural competence for equity and inclusion: A framework for individual and organizational change. Understanding and Dismantling Privilege Journal, 10(1), 524.

Greenberg, J., \& Pyszczynski, T. (1985). The effect of an overheard ethnic slur on evaluations of the target: How to spread a social disease. Journal of Experimental Social Psychology, 21(1), 61-72. https://doi.org/10.1016/0022-1031(85)90006-X

Haddock, G., Zanna, M. P., \& Esses, V. M. (1993). Assessing the structure of prejudicial attitudes: The case of attitudes toward homosexuals. Journal of Personality and Social Psychology, 65(6), 1105-1118. https://doi.org/10.1037/0022-3514.65.6.1105

Hall, E. V., Phillips, K. W., \& Townsend, S. S. M. (2015). A rose by any other name?: The consequences of subtyping "African-Americans" from "Blacks". Journal of Experimental Social Psychology, 56, 183-190. https://doi.org/10.1016/j.jesp.2014.10.004

Hayes, A. F. (2017). Introduction to mediation, moderation, and conditional process analysis: $A$ regression-based approach. Guilford.

Helms, J. E., \& Richardson, T. Q. (1997). How "multiculturalism" obscures race and culture as differential aspects of counseling competency. In D. B. Pope-Davis \& H. L. K. Coleman (Eds.), Multicultural counseling competencies: Assessment, education and training, \& supervision (pp. 60-79). Sage Publications, Inc.

Herek, G. M. (2010). Sexual orientation differences as deficits: Science and stigma in the history of American psychology. Perspectives on Psychological Science, 5(6), 693-699. https://doi.org/10.1177/174569161038877

Herek, G. M., Chopp, R., \& Strohl, D. (2007). Sexual stigma: Putting sexual minority health issues in context. In I. H. Meyer \& M. E. Northridge (Eds.), The Health of Sexual Minorities (pp. 171-208). Springer US. https://doi.org/10.1007/978-0-387-31334-4 8 
Herek, G. M., Gillis, J. R., \& Cogan, J. C. (2009). Internalized stigma among sexual minority adults: Insights from a social psychological perspective. Journal of Counseling Psychology, 56(1), 32-43. https://doi.org/10.1037/a0014672

Hetchkopf, K. (2010, February 11). Support for gays in the military depends on the question. CBS News. https://www.cbsnews.com/news/support-for-gays-in-the-military-dependson-the-question/

Human Dignity Trust (2016). Breaking the silence: Criminalisation of lesbians and bisexual women and its impact. https://www.humandignitytrust.org/wpcontent/uploads/resources/Breaking-the-Silence-Criminalisation-of-LB-Women-and-itsImpacts-FINAL.pdf

Inzlicht, M., \& Ben-Zeev, T. (2000). A threatening intellectual environment: Why females are susceptible to experiencing problem-solving deficits in the presence of males. Psychological Science, 11(5), 365-371. https://doi.org/10.1111/1467-9280.00272

Jones, C. P. (2000). Levels of racism: A theoretic framework and a gardener's tale. American Journal of Public Health, 90(8), 1212-1215. https://doi.org/10.2105/AJPH.90.8.1212

Katz, J. N. (1976). Gay American history: Lesbians and gay men in the USA. Crowell.

Katz, J. N. (1995). The invention of heterosexuality. Dutton.

Kruk, M., \& Matsick, J. L. (in press). A taxonomy of identity safety cues based on gender and race: From a promising past to an intersectional and translational future. Translational Issues in Psychological Science. PsyArXiX Preprint: https://doi.org/10.31234/osf.io/qyr7f

Lekas, H.-M., Pahl, K., \& Lewis, C. (2020). Rethinking cultural competence: Shifting to cultural humility. Health Services Insights. https://doi.org/10.1177/1178632920970580

Liekens, S., Smits, T., Laekeman, G., \& Foulon, V. (2012). Factors determining social distance toward people with depression among community pharmacists. European Psychiatry, 27(7), 528-535. https://doi.org/10.1016/j.eurpsy.2010.12.009 
Link, B. G., Cullen, F. T., Frank, J., \& Wozniak, J. F. (1987). The social rejection of former mental patients: Understanding why labels matter. American Journal of Sociology, 92(6), 1461-1500. https://doi.org/10.1086/228672

López-Sáez, M. A., \& García-Dauder, D. (2020). The masculinity/femininity tests as psychological technologies for gender control. Athena Digital, 20(2), 1-30. https://doi.org/10.5565/rev/athenea.2521

López-Sáez, M. A., García-Dauder, D., Montero, I., \& Lecuona, O. (2021) Adaptation and validation of the evasive attitudes of sexual orientation scale into Spanish, Journal of Homosexuality. https://doi.org/10.1080/00918369.2021.1898803

Maass, A. (1999). Linguistic intergroup bias: Stereotype perpetuation through language. Advances in Experimental Social Psychology, 31, 79-121. https://doi.org/10.1016/S0065-2601(08)60272-5

Matsick, J. L., Kim, L. M., \& Kruk, M. (2020). Facebook LGBTQ pictivism: The effects of women's rainbow profile filters on sexual prejudice and online belonging. Psychology of Women Quarterly, 44(3), 342-361. https://doi.org/10.1177/0361684320930566

Mayfield, W. (2001). The development of an internalized homonegativity inventory for gay men. Journal of Homosexuality, 41(2), 53-76. https://doi.org/10.1300/J082v41n02_04

McConahay, J. B. (1986). Modern racism, ambivalence, and the modern racism scale. In J. F. Dovidio \& S. L. Gaertner (Eds.), Prejudice, discrimination, and racism (pp. 91-125). Academic Press.

Menegatti, M., \& Rubini, M. (2017). Gender bias and sexism in language. In H. Giles and J. Harwood (Eds.), Oxford encyclopedia of intergroup communication (pp. 1-24). Oxford University Press. https://doi.org/10.1093/acrefore/9780190228613.013.470

Meyer, I. H. (2003). Prejudice, social stress, and mental health in lesbian, gay, and bisexual populations: Conceptual issues and research evidence. Psychological Bulletin, 129(5), 674-697. https://doi.org/10.1037/0033-2909.129.5.674 
Morrison, K. R., \& Chung, A. H. (2011). "White” or “European American”? Self-identifying labels influence majority group members' interethnic attitudes. Journal of Experimental Social Psychology, 47(1), 165-170. https://doi.org/10.1016/j.jesp.2010.07.019

Morrison, T. G., Parriag, A. V., \& Morrison, M. A. (1999). The psychometric properties of the homonegativity scale. Journal of Homosexuality, 37(4), 111-126, https://doi.org/10.1300/J082v37n04_07

National Association of Social Workers (2015). Standards and indicators for cultural competence in social work practice. National Association of Social Workers Practice Standards and Guidelines.

Oyserman, D., Uskul, A. K., Yoder, N., Nesse, R. M., \& Williams, D. R. (2007). Unfair treatment and self-regulatory focus. Journal of Experimental Social Psychology, 43(3), 505512. https://doi.org/10.1016/j.jesp.2006.05.014

Pachankis, J. E. (2007). The psychological implications of concealing a stigma: A cognitiveaffective-behavioral model. Psychological Bulletin, 133(2), 328-345. https://doi.org/10.1037/0033-2909.133.2.328

Parks, C. W. (2001). African-American same-gender-loving youths and families in urban schools. Journal of Gay \& Lesbian Social Services, 13(3), 41-56. https://doi.org/10.1300/J041v13n03_03

Peters, J. W. (2014, March 21). The decline and fall of the "H" word. The New York Times. https://www.nytimes.com/2014/03/23/fashion/gays-lesbians-the-term-homosexual.html

Petriglieri, J. L. (2011). Under threat: Responses to and the consequences of threats to individuals' identities. The Academy of Management Review, 36(4), 641-662. https://doi.org/10.5465/amr.2009.0087

Pratto, F., \& Stewart, A. L. (2012). Group dominance and the half-blindness of privilege. Journal of Social Issues, 68(1), 28-45. https://doi.org/10.1111/j.1540-4560.2011.01734.x 
Ricca, P., Wahlskog, C., \& Bergren, M. D. (2018). Enhancing cultural sensitivity in a community health care setting for LGBTQ patients. Journal of Community Health Nursing, 35(4), 165-178. https://doi.org/10.1080/07370016.2018.1516420

Ridley, C. R., Baker, D. M., \& Hill, C. L. (2001). Critical issues concerning cultural competence. The Counseling Psychologist, 29(6), 822-832. https://doi.org/10.1177/0011000001296003

Riggle, E. D. B., Mohr, J. J., Rostosky, S. S., Fingerhut, A. W., \& Balsam, K. F. (2014). A multifactor Lesbian, Gay, and Bisexual Positive Identity Measure (LGB-PIM). Psychology of Sexual Orientation and Gender Diversity, 1(4), 398-411. https://doi.org/10.1037/sgd0000057

Rios, K. (2013). Right-wing authoritarianism predicts prejudice against "homosexuals" but not "gay men and lesbians." Journal of Experimental Social Psychology, 49(6), 1177-1183. https://doi.org/10.1016/j.jesp.2013.05.013

Rossi, A. L., \& Lopez, E. J. (2017). Contextualizing competence: Language and LGBT-based competency in health care. Journal of Homosexuality, 64(10), 1330-1349. https://doi.org/10.1080/00918369.2017.1321361

Rucker, J. M., Murphy, M. C., \& Quintanilla, V. D. (2019). The immigrant labeling effect: The role of immigrant group labels in prejudice against noncitizens. Group Processes \& Intergroup Relations, 22(8), 1139-1160. https://doi.org/10.1177/1368430218818744

Sacchi, S., Brambilla, M., Spaccatini, F., Giovannelli, I., Pacilli, M. G., \& Pagliaro, S. (2021). "If I am straight you are askew": Labelling heterosexuals as straight worsen gay men's perception. Journal of Sex Research, 58(1), 97-105. https://doi.org/10.1080/00224499.2020.1825605

Salomaa, A. C., \& Matsick, J. L. (2019). Carving sexuality at its joints: Defining sexual orientation in research and clinical practice. Psychological Assessment, 31(2), 167-180. https://doi.org/10.1037/pas0000656 
Sarno, E. L., \& Mohr, J. J. (2016). Adapting the multigroup ethnic identity measure to assess LGB group identity. Psychology of Sexual Orientation and Gender Diversity, 3(3), 293303. https://doi.org/10.1037/sgd0000173

Sloboda, A., Mustafa, A., \& Schober, J. (2018). An approach to discussing personal and social identity terminology with patients. Clinical Anatomy, 31(2), 136-139.

\section{https://doi.org/10.1002/ca.23022}

Smith, B. A., Murib, Z., Motta, M., Callaghan, T. H., \& Theys, M. (2018). "Gay" or "homosexual"? The implications of social category labels for the structure of mass attitudes. American Politics Research, 46(2), 336-372. https://doi.org/10.1177/1532673X17706560

Stout, J. G., \& Dasgupta, N. (2011). When he doesn't mean you: Gender-exclusive language as ostracism. Personality and Social Psychology Bulletin, 36(6), 757-769. https://doi.org/10.1177/0146167211406434

Subtirelu, N. (2015, June 2). Why the word "homosexual" is offensive. The Week. https://theweek.com/articles/556341/why-word-homosexual-offensive

Sue, D. W. (2001). Multidimensional facets of cultural competence. The Counseling Psychologist, 29(6), 790-821. https://doi.org/10.1177/0011000001296002

Tajfel, H., Billig, M. G., Bundy, R. P., \& Flament, C. (1971). Social categorization and intergroup behaviour. European Journal of Social Psychology, 1(2), 149-178.

Tavits, M., \& Pérez, E. O. (2019). Language influences mass opinion toward gender and LGBT equality. Proceedings of the National Academy of Sciences, 116(34), 16781-16786. https://doi.org/10.1073/pnas.1908156116

Treisman, R. (2020, September 3). Dictionary.com's largest update (re)defines thousands of words, focusing on identity. National Public Radio. https://www.npr.org/2020/09/03/909494937/dictionary-coms-largest-update-re-definesthousands-of-words-focusing-on-identit 
Truong, N., Perez-Brumer, A., Burton, M., Gipson, J., \& Hickson, D. (2016). What is in a label? Multiple meanings of 'MSM' among same-gender-loving Black men in Mississippi. Global Public Health, 11(7-8), 937-952. https://doi.org/10.1080/17441692.2016.1142593

Van Gilder, B. J. (2019). Sexual orientation stigmatization and identity work for gays, lesbians, and bisexuals in the U.S. military. Journal of Homosexuality, 66(14), 1949-1973. https://doi.org/10.1080/00918369.2018.1522812

Vorauer, J. D. (2006). An information search model of evaluative concerns in intergroup interaction. Psychological Review, 113(4), 862-886. https://doi.org/10.1037/0033295X.113.4.862

Watson, D., Clark, L. A., \& Tellegen, A. (1988). Development and validation of brief measures of positive and negative affect: The PANAS scales. Journal of Personality and Social Psychology, 54(6), 1063-1070. https://doi.org/10.1037/0022-3514.54.6.1063

Zavala-Rojas, D. (2014). Thermometer scale (feeling thermometer). In A. C. Michalos (Ed.), Encyclopedia of quality of life and well-being research (pp. 6633-6634). Springer. 